\title{
Obstetricia \\ USO DO LASER EM CIRURGIA FETAL MINIMAMENTE INVASIVA MITO OU REALIDADE?
}

O uso do laser em Medicina Fetal vem sendo difundido pelo mundo. Sua utilização teve início na década de 1980, baseada na fisiopatologia da síndrome da transfusão feto-fetal (STFF) e por ser considerado cautério frio' '. ASTFF se instala em gestações gemelares devidoà presença de anastomoses vasculares superficiais placentárias comfluxo desbalanceado, praticamente unidirecional, de um feto ao outro. Como conseqüência dessas anormalidades hemodinâmicas ocorrem prejuízos em ambos os fetos, verificando-se, subseqüentemente, índices de mortalidade e de morbidade perinatais muito elevados que se relacionam a riscos de derrame cerebral, insuficiência cardíaca congestiva e, conseqüentemente, ao óbito fetal/neonatal. Antes dessa alternativa terapêutica, foi proposta a amniodrenagem seriada, porém os resultados foram insatisfatórios.

Estudos iniciais com uso de laser na STFF em ovelhas e em macacas, nas décadas de 1970 e 1980, foram entusiásticos. Ao propiciar resultados perinatais aprimorados, a técnica de ablação das anastomoses vasculares interplacentárias foi aperfeiçoada e difundida pelos Estados Unidos e Europa. A superioridade do laser sobre a amniodrenagem foi demonstrada recentemente (sobrevida de pelo menos um feto de $76 \%$ contra $55 \%$, após respectivos procedimentos) $)^{2}$. Assim, até o presente, a literatura evidencia que o laser é a melhor opção terapêutica para a síndrome da transfusão feto-fetal nos estágios graves. Porém, mesmo com essa opção terapêutica, não se consegue salvar ambos os fetos em aproximadamente 50\% dos casos. Uma das explicações possíveis para esse fato seria o amplo espectro clínico da STFF, com situações leves (estágio I) até aquelas com óbito de um feto (estágio V), além de muitos casos serem referidos tardiamente ${ }^{3}$. Com casuística de seis procedimentos até o momento, na Clínica Obstétrica do Hospital das Clínicas da Faculdade de Medicina da Universidade de São Paulo, a técnica de ablação vascularfoi viabilizada e preconizada para o tratamento com laser para os casos graves (estágios II, III e IV).

Além daSTFF, a aplicação do laser em Medicina Fetal se estende para outros distúrbios fetais, porém ainda são considerados procedimentos experimentais. São eles: cauterização dos vasos de tumores hipervascularizados que causam hidropisia fetal (como teratoma sacrococcígeo) ${ }^{4}$, fulguração da válvula de uretra posterior guiada pela cistoscopia fetal e a ablação do vaso anômalo nos seqüestros broncopulmonares com hidropisia. Esses procedimentos são oferecidos no Serviço ainda em caráter experimental, sendo motivo de estudos randomizados. 
Como conclusão, pode-se afirmar que o uso do laser em Medicina Fetal é uma realidade promissora, pois se baseianafilosofia de se aplicar procedimentos minimamente invasivos em terapias antenatais e na fisiopatologia dos distúrbios fetais, além de ser comprovadamente exeqüível. Entretanto, em que pese a vasta experiência no exterior, a técnica careceainda de comprovação científica, especialmenteno Brasil, poisé claramente dependente da seleção dos candidatos e de equipes amplamente habilitadas para a aplicação de tais procedimentos para constituição de casuística encorpada.

Rodrigo RUANO

ROBRo ZuGa

Referências

I.DeVore GR, Dixon JA, Hobbins JC. Fetoscope-directed neodymium-YAG laser: a potential tool for fetal surgery. Am J Obstet Gynecol. 1983; | 45(3):379-80

2.Senat MV, Deprest J, Boulvain M, Paupe A, Winer N, Ville Y. Endoscopic laser surgery versus serial amnioreduction for severe twin-to-twin transfusion syndrome. N Engl J Med. 2004;35।(2):|36-44

3.Fisk NM, Tan TY, Taylor MJ. Re: Stage-based treatment of twin-twin transfusion syndrome. Am J Obstet Gynecol. 2004;190(6): |809-10.

4.Hecher K, Hackeloer B]. Intrauterine endoscopic laser surgery for fetal sacrococcygeal teratoma. Lancet. 1996;347(8999):470. 